\title{
Homograft valve repair for recurrent prosthetic valve endocarditis
}

\author{
Richard Lee, MD, and Marc R. Moon, MD, St Louis, Mo
}

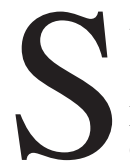

urgical management of prosthetic valve endocarditis (PVE) remains a formidable challenge, especially for patients who continue intravenous drug use after successful initial treatment. ${ }^{1,2}$ In an effort to reduce the rate of recurrent endocarditis, strategies including aortic valve repair and aortic root replacement with a homograft have been reported. ${ }^{1,3}$ However, recurrent endocarditis of an aortic homograft represents a clinical problem without a well-established solution. This report details the treatment of a second recurrence of PVE in an intravenous drug user who had undergone homograft root replacement 11 months previously for endocarditis of an aortic valve bioprosthesis.

\section{Clinical Summary}

A 43-year-old woman with diabetes mellitus and a 25-year history of intravenous drug use was seen in June 2000 with a history of fever, chills, and a cough for several weeks. Blood cultures revealed Streptococcus sanguis. Transthoracic echocardiography revealed severe aortic insufficiency and a large vegetation on the noncoronary cusp of the valve. The development of severe congestive heart failure necessitated aortic valve replacement. At the operation, the noncoronary cusp was completely destroyed but the annulus was spared, so a bioprosthetic valve was inserted. ${ }^{4}$ After the operation the patient received 4 weeks of organism-specific antibiotic therapy and was discharged to a drug rehabilitation center.

Three months later (September 2000), she was seen with fever and chills after resumption of intravenous drug use. Transesophageal echocardiography demonstrated no vegetations or abscesses. Blood cultures revealed Staphylococcus aureus. Initially, the patient was treated with intravenous vancomycin; however, she refused to return to a drug rehabilitation center and was discharged against medical advice with an oral course of antibiotics.

Three months later (December 2000), she returned in severe congestive heart failure with a perivalvular leak and an extensive aortic root abscess that involved more than half of the annulus. Aortic root replacement was therefore performed with an aortic

From the Division of Cardiothoracic Surgery, Washington University School of Medicine, St Louis, Mo.

Received for publication May 16, 2002; accepted for publication June 13, 2002.

Address for reprints: Marc R. Moon, MD, Division of Cardiothoracic Surgery, Washington University School of Medicine, 3108 Queeny Tower, No. 1 Barnes-Jewish Plaza, St Louis, MO 63110 (E-mail: moonm@msnotes.wustl.edu).

J Thorac Cardiovasc Surg 2003;125:725-7

Copyright (C) 2003 by The American Association for Thoracic Surgery $0022-5223 / 2003 \$ 30.00+0$

doi: $10.1067 / \mathrm{mtc} .2003 .143$ homograft. She did well postoperatively and agreed to go to an extended care facility for further antibiotic treatment.

Eleven months later (November 2001), she was seen again with fever and chills, again after resumption of intravenous drug use. Transesophageal echocardiography revealed a $1.5-\mathrm{cm}$ vegetation on the left coronary cusp of her aortic homograft valve (Figure 1). Blood cultures revealed Streptococcus mitis. Despite 10 days of organism-specific antibiotic therapy, the vegetation enlarged, and the patient remained septic. At the operation, inspection of the valve revealed an irregular vegetation on the left coronary cusp without involvement of the other two leaflets, annulus, or neoaorta. The vegetation was completely excised with, a 2-mm rim of homograft valve tissue (Figure 2, A). A $2 \times 1-\mathrm{cm}$ crescent-shaped piece of bovine pericardium was used to reconstruct the left coronary cusp with 5-0 polypropylene suture in a running fashion (Figure 2, B). Intraoperative transesophageal echocardiography revealed trivial aortic insufficiency. The patient recovered well and was discharged to a rehabilitation center, where she received intravenous antibiotics. At 5 months after this latest episode, the patient remains symptom free, has not resumed intravenous drug use, and has trivial aortic insufficiency according to transthoracic echocardiography.

\section{Discussion}

PVE is a rare complication after valve replacement for noninfectious causes. ${ }^{5}$ However, the risk of PVE of a valve that was originally placed because of endocarditis is at least 7-fold higher, approaching $10 \% .^{1,6}$ For patients who resume intravenous drug use, the recurrence rate may exceed $40 \% .^{2}$

Aortic valve repair has been used effectively but sparingly for treatment of native valve endocarditis. ${ }^{3}$ For recurrent infections involving an aortic valve prosthesis with an extensive abscess, homograft root replacement is the procedure of choice. Homograft valves are associated with a diminished risk of early PVE, 1,6 although a recent meta-analysis revealed that the early protective resistance to recurrent infection does not persist in the long term. ${ }^{6}$

For our patient with multiply recurrent PVE, the options were limited. Prosthetic homograft valve repair was chosen, and although the durability of such a repair is entirely unknown, it afforded the patient with an opportunity for her infection to clear. If the patient can avoid intravenous drug use, a more permanent solution can be offered at a later date should the valve fail. To the best of our knowledge, valve repair of an aortic homograft has not been reported previously, but the application of this technique, in lieu of reoperative homograft root replacement, greatly reduced both the ischemic time and complexity of the operation. This probably contributed to the successful outcome to date. We therefore believe that valve repair should be considered for patients with active homograft endocarditis if anatomically feasible. 


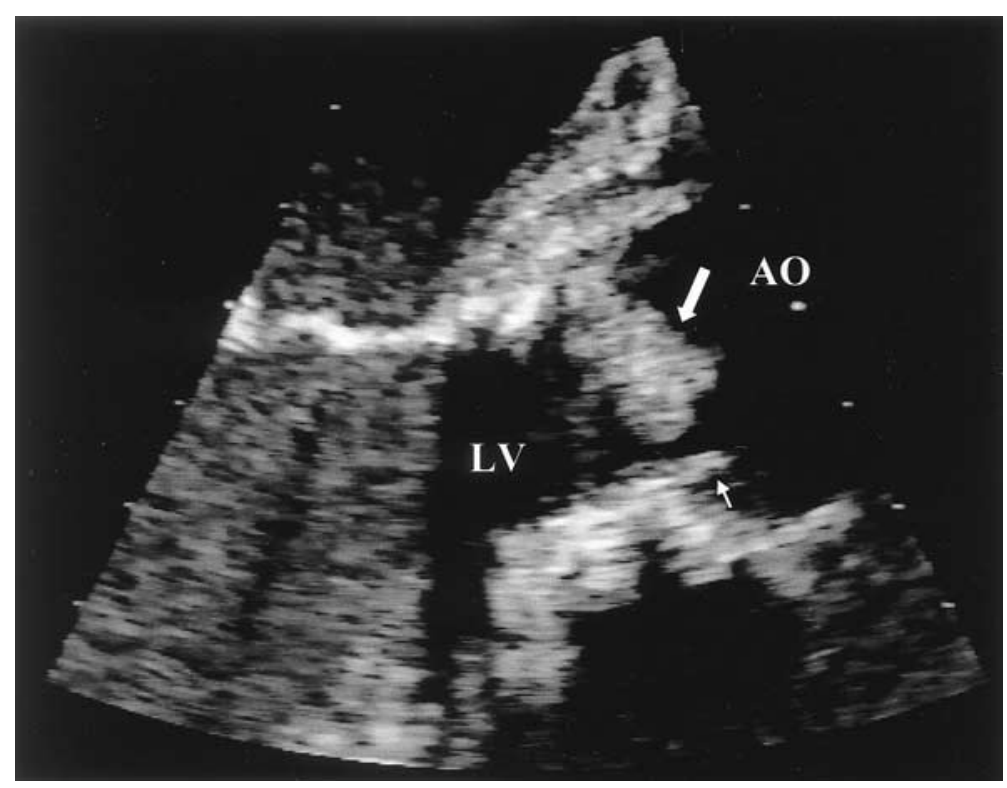

Figure 1. Transesophageal echocardiographic image demonstrating 1.5-cm vegetation on left coronary cusp (large arrow) of aortic homograft. Small arrow indicates uninvolved right coronary cusp. AO, Aorta; $L V$, left ventricle.
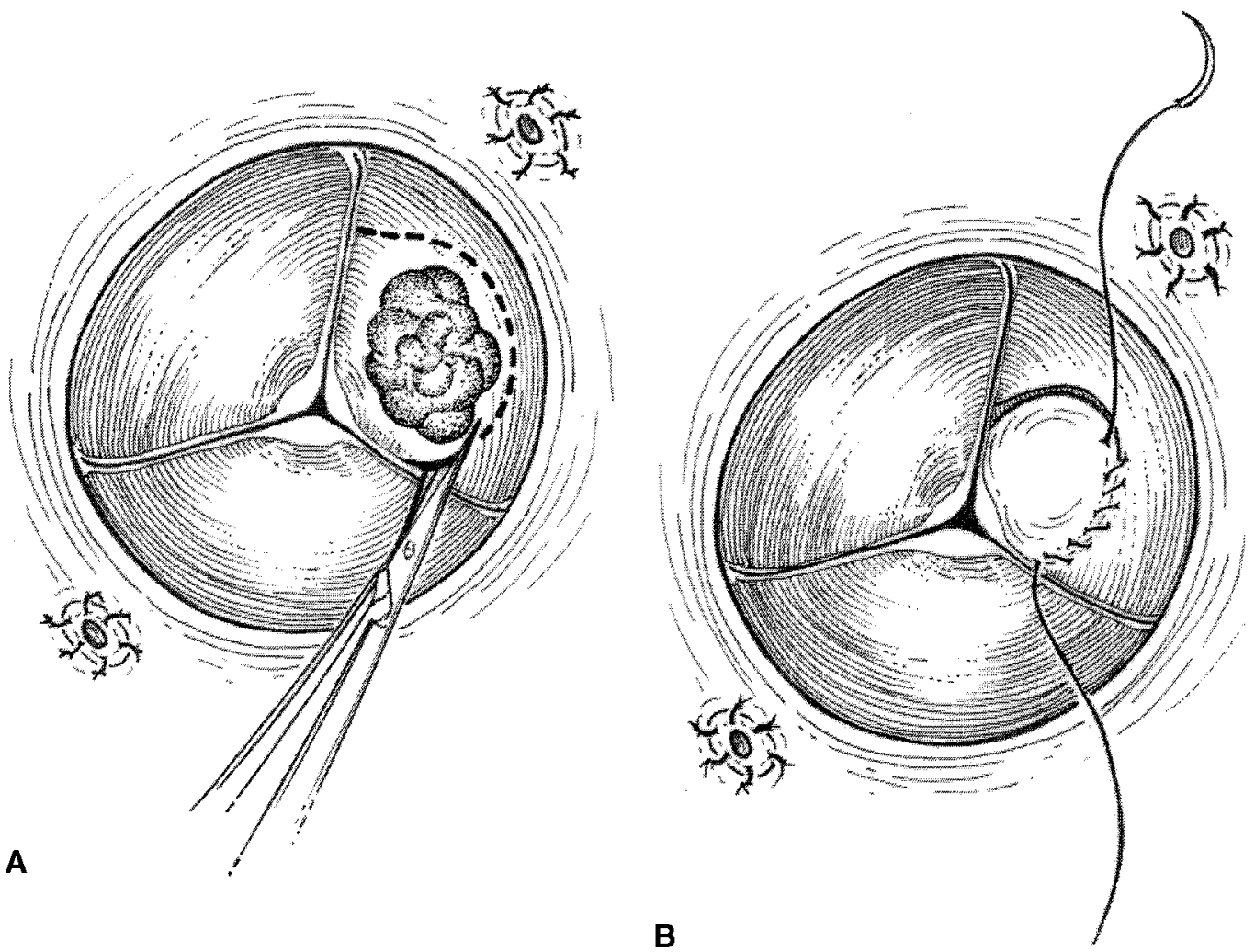

Figure 2. Technique of aortic homograft valve repair. A, Excision of left coronary cusp containing vegetation and 2-mm rim of healthy tissue. B, Placement of bovine pericardial patch to reconstruct cusp. 


\section{References}

1. Moon MR, Stinson EB, Miller DC. Surgical treatment of endocarditis. Prog Cardiovasc Dis. 1997;40:239-64.

2. Arbulu A, Asfaw S. Management of infective endocarditis: seventeen years' experience. Ann Thorac Surg. 1987;43:144-9.

3. Rao V, Van Arsdell GS, David TE, Azakie A, Williams WG. Aortic valve repair for adult congenital heart disease: a 22-year experience. Circulation. 2000;102(19 Suppl 3):III40-3.

4. Moon MR, Miller DC, Moore KA, Oyer PE, Mitchell RS, Robbins
$\mathrm{RC}$, et al. Treatment of endocarditis with valve replacement: the question of tissue versus mechanical prosthesis. Ann Thorac Surg. 2001;71:1164-71.

5. Gordon SM, Serkey JM, Longworth DL, Lytle BW, Cosgrove DM. Early onset of prosthetic valve endocarditis: the Cleveland Clinic experience 1992-1997. Ann Thorac Surg. 2000;69:1388-92.

6. Grunkemeier GL, Hui-Hua L. Epidemiology and risk factors for prosthetic valve endocarditis. In: Vlessis AA, Bolling S, editors. Endocarditis: a multidisciplinary approach to modern treatment. Armonk, NY: Futura Publishing; 1999. p. 85-103.

\title{
Initial experience with a stentless porcine bioprosthesis for right ventricular outflow tract reconstruction in children
}

\author{
Luca A. Vricella, MD, Michael A. Coady, MD, and Michael D. Black, MD, Stanford, Calif
}

$\mathrm{P}$ ostoperative pulmonary regurgitation and stenosis still remain major determinants of long-term outcome in children requiring right ventricular outflow tract (RVOT) reconstruction.

Because of relatively low right-sided pressures, mechanical valves are at high risk for thrombosis, and long-term anticoagulation is disadvantageous in pediatric patients for obvious reasons. ${ }^{1}$ Because of accelerated calcification, bioprosthetic valves are, on the other hand, likely to undergo structural valve deterioration in younger patients. ${ }^{2}$

The use of a stentless valve design, with improved shear stress on the valve leaflets, might prevent early valvular calcification. The Toronto stentless porcine valve (SPV; St Jude Medical, Inc, St Paul, Minn) incorporates a flexible Dacron ring with lack of an accompanying aortic wall. We hypothesized that these distinguishing characteristics might allow for improved long-term function when used in RVOT reconstruction in children.

\section{Clinical Summary}

Nine patients ( 8 male patients and 1 female patient) born with tetralogy of Fallot underwent RVOT reconstruction with Toronto SPVs between March 1998 and July 2001. Mean age and weight were, respectively, 11.2 years (range, 4-17 years) and $41.6 \mathrm{~kg}$

\footnotetext{
From the Division of Pediatric Cardiac Surgery, Lucile Packard Children' Hospital at Stanford, Stanford University School of Medicine, Stanford, Calif.

Received for publication Dec 7, 2002; accepted for publication Aug 27 2002.

Address for reprints: Michael D. Black, MD, Pediatric Cardiac Surgery, Lucile Packard Children's Hospital, Stanford University School of Medicine, Stanford, CA 94305-5407 (E-mail: Michael.black@leland.stanford. edu).

J Thorac Cardiovasc Surg 2003;125:727-8

Copyright $\odot 2003$ by The American Association for Thoracic Surgery $0022-5223 / 2003 \$ 30.00+0$

doi: $10.1067 / \mathrm{mtc} .2003 .22$
}

(range, 15.2-83.1 kg). Preoperative patient characteristics and surgical indications are summarized in Table 1. All but one procedure were reoperative, with surgical indications being RVOT stenosis $(n=4)$ or pulmonary insufficiency $(n=5)$. Intraoperative transesophageal echocardiography was performed in all patients, and transthoracic echocardiograms were obtained at various intervals

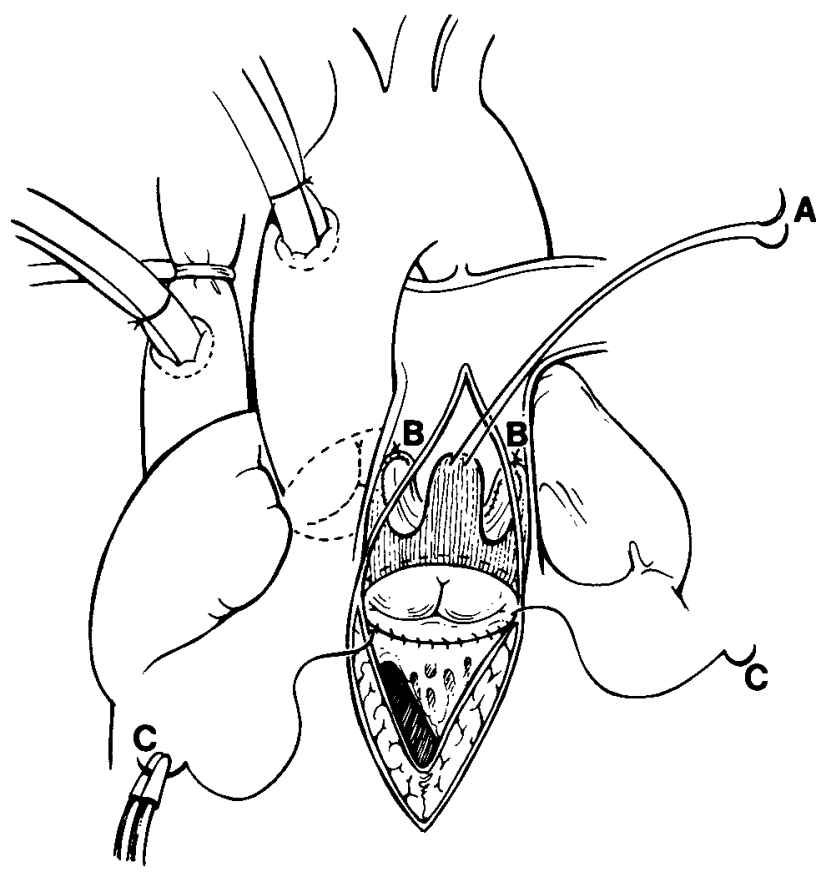

Figure 1. Insertion of an SPV in the subannular position within the RVOT before patch arterioplasty: $A$, mattress suture securing the anterior SPV commissural post to the RVOT patch; B, sutures spacing the posterior posts at $120^{\circ}$ distance to protect the right and left pulmonary ostia; $C$, continuous proximal suture. The anterior $120^{\circ}$ of the suture line are passed transversely across the RVOT patch. 